\title{
Article \\ Industry 4.0 and the Circular Economy: Integration Opportunities Generated by Startups
}

\author{
Tiago H. H. Silva (D) and Simone Sehnem * D
}

Citation: Silva, T.H.H.; Sehnem, S. Industry 4.0 and the Circular

Economy: Integration Opportunities Generated by Startups. Logistics 2022, 6, 14. https://doi.org/10.3390/ logistics6010014

Academic Editor: Robert Handfield

Received: 15 December 2021

Accepted: 25 January 2022

Published: 7 February 2022

Publisher's Note: MDPI stays neutral with regard to jurisdictional claims in published maps and institutional affiliations.

Copyright: (C) 2022 by the authors. Licensee MDPI, Basel, Switzerland. This article is an open access article distributed under the terms and conditions of the Creative Commons Attribution (CC BY) license (https:// creativecommons.org/licenses/by/ $4.0 /)$.
Department of Management, Universidade do Sul de Santa Catarina-Unisul, Palhoça 79624, SC, Brazil; tiago.hennemann.dasilva@gmail.com

* Correspondence: simonesehnem_adm@yahoo.com.br

\begin{abstract}
Background: The purpose of this study is to analyze the adoption and implementation of technologies related to Industry 4.0 and the integration with circular economy (CE) to minimize the effects of resource scarcity in emergency situations. Method: The study was developed in two stages: The first consists of a systematic review of the literature for analytical categorization of the technologies of Industry 4.0 that can be useful for implementation in the circular economy. In the second step, empirical validation was carried out with 45 foodtech startups from the agribusiness value chain, farm to table, reuse, and waste management and disposal segments. Results: The contributions of the study show that: (i) The business models of startups in the food segment are closely aligned with the assumptions of circular economy. (ii) The technologies of industry 4.0 are supporting the implementation of circular economy in foodtech companies. (iii) Digitization, traceability, software as a service, traceability, digital solutions, and shared platforms occupy the leadership in the interface between CE and industry 4.0. (iv) Partnerships are strategic elements in the creation of innovative ecosystems for the success of foodtech startups. Conclusions: We conclude this paper with a diagnosis about companies involved in the foodtech segment in addition to the proposition of a business and sectorial agenda to consolidate the Industry 4.0 technologies in order to promote circular economy.
\end{abstract}

Keywords: sustainability; startups; circular supply; circularity of resources; smart assets

\section{Introduction}

Globally, we have been experiencing enormous instability [1]. Several phenomena, namely the pandemic caused by COVID-19 [2], climate change [3], the urgent need to learn how to efficiently manage the waste that human beings produce [4], the asymmetries between hunger and food waste [5], economic instabilities [6], and natural disasters [7], signal an urgent need to rethink our processes and production models. And this demands adherence to new alternatives that already exist, such as Industry 4.0, artificial intelligence, and new ways of producing, which allow the circularity of resources [8].

In this perspective, this study aims to answer the following research question: how are organizations adopting and implementing technologies related to Industry 4.0 and promoting the integration with circular economy to minimize the effects of resource scarcity in emergency situations? To understand this social phenomenon, first, we look at the existing literature to identify what has already been unveiled on this subject. With these data in hand, it was possible to analyze the adoption and implementation of technologies related to Industry 4.0 and the integration with circular economy to minimize the effects of resource scarcity in emergency situations. That being done, we elaborated theoretical propositions for empirical validation in an organizational context considering startups. The main contribution of this study is the development of insights that bring about an important venue to contribute to the adoption and implementation of technologies related to Industry 4.0 and the integration with circular economy to minimize the effects of resource scarcity in emergency situations through innovative alternatives. 
Industry 4.0 presents a set of technological artifacts that can be useful in the transition towards circular economy and generate productive chain, integration, connectivity, solutions, data, interactivity, synergy, and mechanisms to produce sustainable supply chains that are in line with the precepts of companies committed to the circularity of resources.

The structure of the paper includes a theoretical section that addresses existing interfaces between Industry 4.0 and circular economy. The methodology section presents the path taken to conduct this research. The presentation, analysis, and discussion of the research results are followed by the final considerations.

\section{Interfaces between Industry 4.0 and Circular Economy}

Industry 4.0 consists of a set of technologies that combine artificial intelligence (AI), intelligent sensors [9], big data, and cloud computing and are considered as the basis of the infrastructure of a smart grid [10]. Manufacturing industries that adhere to Industry 4.0 technologies are expecting transformational and promising solutions [11]. These changes within the smart grid infrastructure use network resources in a highly distributed manner [12].

For this study, we used the core definition of circular economy, that is, promulgating the decoupling of economic activity from the unlimited consumption of finite resources [13]. This ensures the use of renewable energies in production processes and eliminates the generation of waste in the system by acting on the root cause of its generation. It also enacts durability, longevity, the extension of the life cycle of materials and products, and the regeneration of materials via technical and biological cycles [14].

For Industry 4.0, we adopted as concept the set of technologies that can connect the physical, digital, and biological worlds [15]. They encompass artifacts such as artificial intelligence, robotics, big data, additive manufacturing, IoT, synthetic biology, and physical cyber systems [16]. It impacts productivity, cost reduction, control over production processes, customization of production, and in-depth transformation of manufacturing plants [17]. It also involves efficiency gains and reduced maintenance costs and energy consumption [18].

Artificial intelligence comprises the set of technologies that include machine learning and natural language processing, which enable machines to feel, understand, act, and learn [19]. It is a framework with the potential to transform the relationship between people and technologies [20]. They have implications for the creativity and competences of human beings, in addition to the potential for disruption and productivity, with the ability to rapidly and precisely improve human ingenuity and genius [21].

It is understood that circularity adopts the perspective of acting in a cyclical way through the engagement of all links in the productivity chain. This encourages reuse, recycling, reverse logistics, longevity, ecoefficiency, and levels of circularity [22]. Digital technologies, in turn, are understood as an elementary support for the transition towards circular economy, especially because they have the power to provide alternatives for processes' virtualization, dematerialization, transparency, and intelligence generated in feedback mechanisms [23].

In this context, we list solutions provided by Industry 4.0 and AI for the implementation of circular economy and circularity in production chains. They are supported in a basic way by the studies of [24-34]. They are:

(a) Integration of ubiquitous and intelligent components in supply chains: Industry 4.0 provides a set of elements that contribute to cost reduction in production chains and allow the measurement of results in terms of remote sensing, traceability, realtime monitoring and control results, and nonconformities [35]. In this sense, the main contribution of Industry 4.0 to the advancement of CE is associated with the promotion of incentives for cleaner production systems, ethical production systems, transparency in processes, and precision, accuracy, and efficiency in process control. It allows for generating data on the volume of resources used, and devices with RFID tags can assist in the management of the reverse logistics of obsolete materials for 
possible dematerialization and conversion into new useful resources for new economic production cycles. Therefore, Industry 4.0 can be considered a foundation of CE and can expand the circularity of resources within production and consumption systems within the macro, meso, micro and nano circularity levels.

(b) Digitization: The digital transformation has incorporated in manufacturing industrial processes alternatives oriented to data management, artificial intelligence, networks, and resilient manufacturing systems [35]. This demonstrates that digitization contributes to $\mathrm{CE}$ via data generation, cost reduction in processes, provision of information for decision making with real time precision. Above all, it contributes to the generation of self-adaptability, reliability, and flexibility with the insertion of high-quality, low-cost, do-it-yourself assumptions, and customization in production processes.

(c) Smart Factory: Smart factories are structures that contribute greatly to reducing waste and supporting the efficiency of operating and processing systems. They allow the self-configuration of these operating systems and the adoption of integrated manufacturing system strategies [36]. This generates, as a contribution to CE, the closing of the cycles and the possibility of creating an articulation between the stakeholders of the production chain to generate synergies and win-win results.

(d) Deep learning: The use of a set of algorithms for modeling attractions is an innovative perspective to leveraging $\mathrm{CE}$. Its usefulness is associated with understanding customer behavior when used in e-commerce sites. It allows the collection of customer data during the entire period in which it is connected to a URL. This data generated with the use of deep learning is utilized to optimize the website and to make the browsing experience more engaging for the customer. The facial recognition utility can be useful for $\mathrm{CE}$ to connect relevant stakeholders and produce synergies in integrated supply chains. Furthermore, it can provide personalized technical support on websites that disseminate the premises of CE. Thus, remote technical assistance to the customer is now provided by a machine. Finally, it allows the issuance of high-precision image diagnostics, which can be essential to monitor indicators of circularity of resources.

(e) Machine learning: Through machine learning, computers have the ability to learn according to the expected response via association of different data. The data can be images, numbers, maps, photographs, etc., and they correspond to gigantic databases.

(f) Big Data: Big data allows data to be virtualized so that they can be stored in the most efficient and economical way. This occurs either on-premises or in cloud. In addition to efficiency, big data also helps in improving the speed and reliability of the network. It removes other physical limitations associated with bulk data management.

(g) Artificial Neural Networks: Computational neural networks that recognize patterns can be useful in the traceability of products that are made available to the market. They are essential for creating a database containing information on final product disposal, strategic points for collecting obsolete materials, and strategic regions for installing associations that manage waste.

(h) Natural Language Processing: Natural language processing allows automatic learning through accumulated data in which automatic rules are applied. Through the analysis of typical elements of the real world and instead of using general algorithms, this technology generates learning based on past real-life examples. This learning usually takes place based on statistical inference.

(i) Expert Systems: Expert systems contribute to CE through data capture and sharing.

(j) Fuzzy Systems: Fuzzy systems make it possible to translate the inaccurate information expressed in a set of linguistic rules into mathematical terms. As a result, it creates a rule-based inference system. This mathematical tool can be used in CE for agile decision making and in the performance of controls, classification, series forecasting, data mining, planning, and optimization. They are associated with other intelligent systems, such as neural networks and evolutionary programming; they provide the creation of hybrid systems, whose learning capacity has broadened the field of applications of fuzzy systems. 
(k) Convolutional Neural Networks: Convolutional neural networks consist of a class of artificial neural network of the feed-forward type. Its applicability is focused on the processing and analysis of digital images. Convolutional neural networks can be used in the $\mathrm{CE}$ to capture an input image, assign importance (weight and bias that can be learned), and obtain the aspects/characteristics/peculiarities of the object, allowing for the differentiation of objects from one another, for example, identifying whether an object was manufactured with reused raw materials from an object that used virgin materials.

(l) Advanced Manufacturing: Advanced manufacturing promotes integration and remote production control. It uses sensors and equipment connected in a network, that is, automation systems associated with cyberphysical systems. It generates integration between assembly lines and products throughout the manufacturing and production process. It helps units in different places to exchange information instantly, including purchases and stocks. $\mathrm{CE}$ is useful due to the ability to activate production without human presence, maintain precision, the continuous and tailor-made manufacturing, the very low defect rate, and the different components of a logistics system. The crossing of information allows the connection between the purchase order, production, and distribution. This signals that people will be needed to make the decisions, which will imply new forms of management and engineering in the entire production line. This movement is supported by the continuous advances in the capacity of computers and software-user interfaces and the digitization of information, which ranges from product design, testing with materials, prototype, layout, organization of the production line, to factory inventories. Additionally, new innovation strategies are being driven by integrated systems of intelligent, mechanical, and electronic technologies. In this context, technologies that direct $\mathrm{CE}$ actions are collaborative robotics, autonomous transport, AI, mobile technology, cloud computing, big data, crowdsourcing, new energy sources, Internet of Things, additive manufacturing, nanotechnology, biotechnology and genetics, new materials, among others.

(m) Automation: It emerges as a possibility for developing ethical business practices and implementing CE effectively. It can be used for predictive purposes or for cognitive analysis [37].

(n) Smart sensors: They are devices that are sensitive to certain magnitudes. They can change the state of a magnitude once they are provided with the right stimuli. They detect movement, temperature change, and opening and closing. They can be used as security devices and as automatic notification by smartphone. They contribute to the development of systems that optimize, update, and reconfigure tasks. They are useful in the monitoring of processes and in the agility in decision making. Therefore, they are artifacts that contribute to $\mathrm{CE}$ through the potential for traceability, precision of industrial indicators, and generation of data in real time for accurate decision making.

(o) RFID: RFID (acronym for Radio-Frequency Identification) is a short-range communication technology, and RFID tags can be read automatically by sensors, for example, at the exit of the supermarket, thus eliminating the manual and individual work of reading bar codes. The radio frequency identification system can act on several fronts, ranging from medical and veterinary applications to the use for payment and replacement of bar codes. It can contribute to the activation of $\mathrm{CE}$ through payment via cell phone, payments in traffic, toll collection, parking, inventory control, cargo tracking, animal tracking, sports modalities for measuring each competitor's lap time, and in biometric identification.

Therefore, industry 4.0 and AI contribute to improving the competitiveness of the manufacturing industries and supporting machine-machine and man-machine interactions. Industry 4.0 is driven by real-time data [38]. It provides alternative approaches to achieve sustainable production and consumption that minimize waste, energy consumption, and environmental deterioration [39]. The idea of Industry 4.0 is ubiquitous and is one of the main targeting strategies to address the 3 Rs (reduce, reuse, and recycle) to achieve 
sustainable production and consumption. The technologies that support industry 4.0 are cyber-physical systems (CPS), Internet of Things (IoT), big data, and cloud computing. They are essential for CE as they corroborate cleaner production, reduced lead time, and optimized inventory [40]. Therefore, they are technologies that have the potential to improve the efficiency of production chains and the precision of production systems while positively impacting circularity indicators.

Finally, AI offers mechanisms to meet dynamic and volatile market demands. It promotes an innovative way of exploring the underlying challenges and limitations of the linear economy. It offers mechanisms that contribute to implementing the concepts of restoration and regeneration in organizations, as well as tracking components used in manufacturing fed by inputs from the dematerialization promoted by CE. Therefore, it is essential to generate a cleaner production system based on the assumptions of $\mathrm{CE}$.

\section{Methodological Procedures}

The study was carried out in two stages: In the first, a systematic literature review was carried out in order to understand the dimensions of Industry 4.0, the circular economy and its interfaces. In the second, empirical validation was carried out in the organizational context of foodtech startups.

The performance of this systematic literature review included the search for systematic literature reviews previously published in the database Scopus and WoS. The search terms adopted were "circular economy" OR "circular econom" AND "artificial intelligence" OR "Industry 4.0" OR "digital technologies" OR "smart factory" OR "deep learning" OR "machine learning" OR "artificial neural networks" OR "natural language processing" OR "expert systems" OR "fuzzy" OR "convolutional neural network" OR "advanced manufacturing". The Scopus and WoS databases were consulted and are considered the largest and with the greatest coverage of journals. The search was carried out on 17 January 2021. A total of 263 papers were found, the duplicates were removed, and the inclusion criteria were applied (area: business management and accounting, type of paper: article, research paper, and review, language: English, Portuguese, or Spanish), and 68 were left to be analyzed in full. However, it was only possible to get access to the full text of 52 articles because some were published as expanded abstracts and others were articles ahead of print, i.e., access to the full paper was not provided. Contact was made with the authors, but it was not possible to access the full paper in a timely manner to complete this study.

After a detailed reading of each article, categories of analysis were created to systematize the main evidence from previous studies published in the field of circular economy and Industry 4.0. For this phase, the research protocol proposed by [41] was followed. Although this protocol was designed to synthesize qualitative case studies, for our study it was adapted to systematize the main evidence of systematic literature reviews published previously. Ref. [41] proposes eight steps to synthesize findings from qualitative studies and to create a theory. They are:

1. Framing the Research Question: Our research question is, "How are organizations adopting and implementing technologies related to Industry 4.0 and promoting the integration with circular economy to minimize the effects of resource scarcity in emergency situations?"

2. Locating Relevant Research: Verification of the Scopus database, the largest, most comprehensive, and most relevant in the scientific management and business community, and WoS, which is the second largest in the area.

3. Inclusion/Exclusion Criteria: Search terms are "circular economy" OR "circular econom*" AND "artificial intelligence" OR "Industry 4.0" OR "digital technologies" OR "smart factory" OR "deep learning" OR "machine learning" OR "artificial Neural Networks" OR "natural language processing" OR "expert systems" OR "fuzzy" OR "convolutional neural network" OR "advanced manufacturing".

4. Extracting and Coding Data: Profile data, i.e., evidence that allows for the understanding of how the social phenomenon under investigation occurs. 
5. Analyzing on a Case-Specific Level: The main aspects regard the existing interface between Industry 4.0 and the circular economy that have been investigated in previous studies.

6. Synthesis on a Cross-Study Level: Performing thematic categorization and theoretical saturation are used to identify the relevant categories for the study. Subsequently, the cross-analysis of the mapped evidence was carried out.

7. Building Theory from Meta-Synthesis: Variables were synthesized around different aspects referring to the existing interfaces between Industry 4.0 and circular economy. Based on this general diagnosis, several proposals were made through a business and sectoral agenda in order to contribute as potential advances to the theme, which were validated in the context of Brazilian startups.

8. Discussion: A critical reflection was made on the contributions of Industry 4.0 and circular economy in a context of global emergency, in the awakening of possibilities for the fulfillment of sustainable development objectives, and in the 2050 business agenda.

Also, a theoretical-empirical study was carried out in the Brazilian foodtech sector. These organizations were accessed via Startup Scanner, a digital platform developed by Liga Ventures with the strategic support of PwC Brasil. The scanner provides the map of Brazilian startups, including foodtech, in a dynamic way and with constant updating. All foodtech startups in the agribusiness value chain, farm to table, reuse, and waste management and disposal segments were accessed in this research. This totaled 45 companies surveyed. Interviews were conducted and data collected through secondary sources, namely, technical reports, flyers, websites, and journalistic reports.

In possession of the data, a qualitative analysis was carried out, following the analytical phases of compilation, decomposition, recomposition, rearrangement, interpretation, and conclusion recommended by [42]. Categorical and cross-case analyses were adopted. The data coding process was performed using an Excel spreadsheet, where each case/foodtech startup was transformed into a data line. This allowed for a cross-sectional, inter-case analysis to be carried out. Figure 1 shows the research design followed in this study.

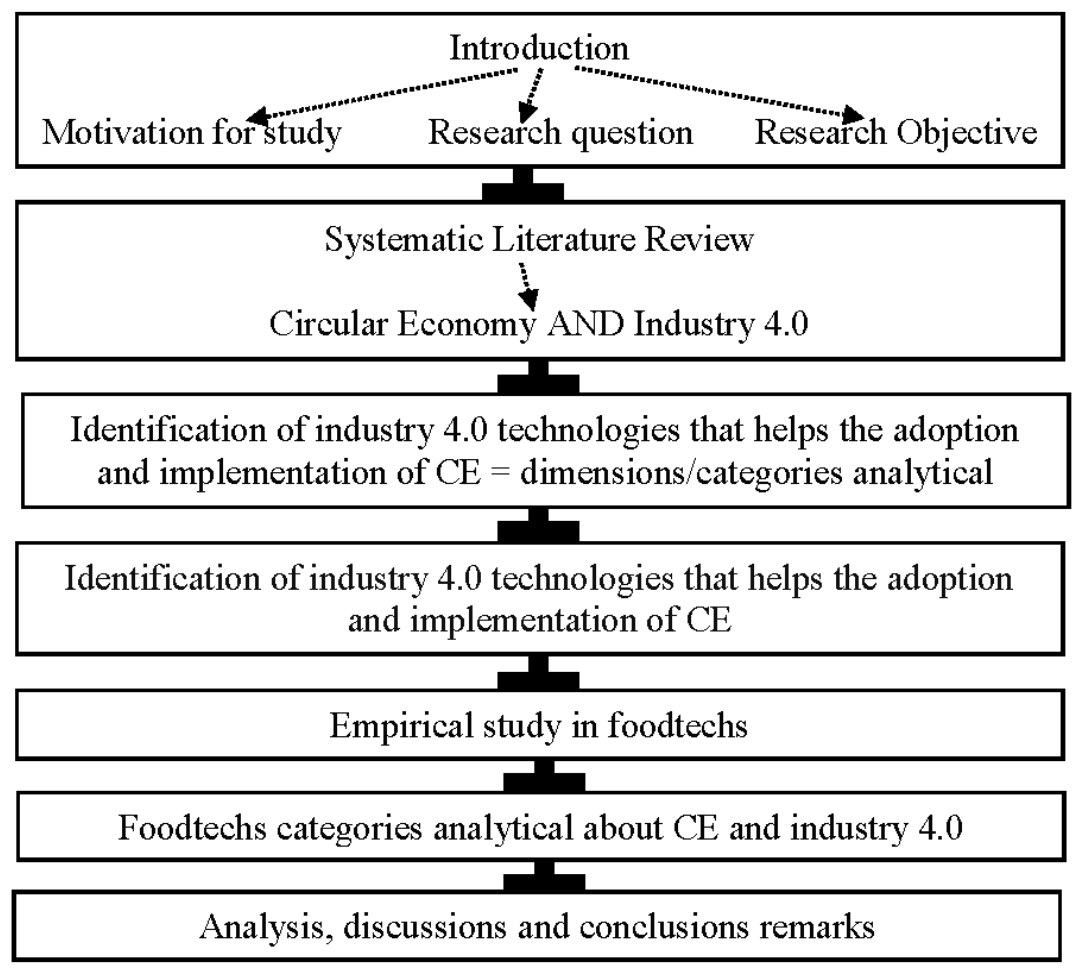

Figure 1. Flow of the study. 
Therefore, the purpose of this study is to identify the technologies of Industry 4.0 that support the adoption and implementation of CE. Based on these systematized data, we presented propositions for business and sectoral agenda, and potential venues for advancement of CE and Industry 4.0 in the startup segment, especially in the foodtech niche.

\section{Data Presentation and Analysis}

Figure 2 presents a brief profile of the articles that were analyzed.

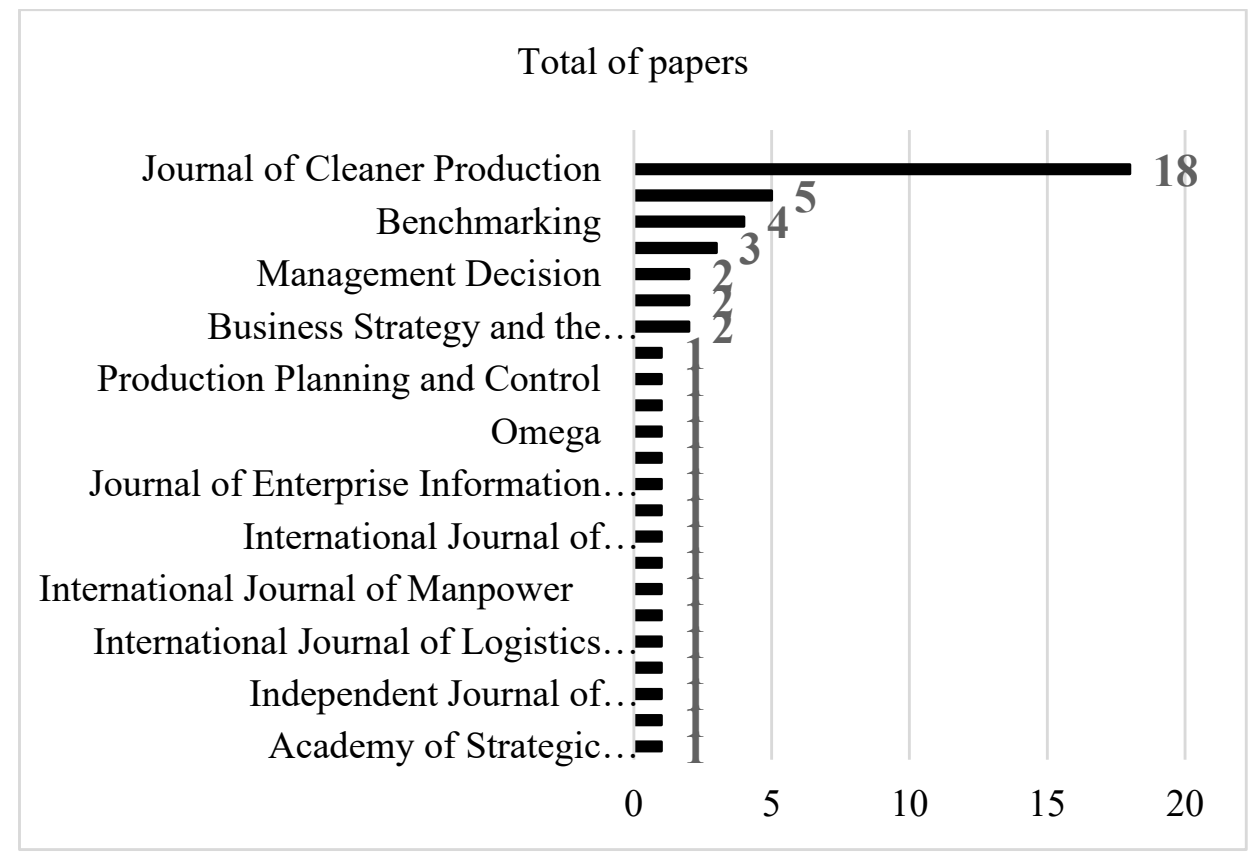

Figure 2. Papers by each journal analyzed.

Figure 2 shows that the journals that stand out are the Journal of Cleaner Production, Journal of Manufacturing Technology, Benchmarking, and Technological Forecasting and Social Change. They are responsible for $57.69 \%$ of the papers that were analyzed in this study. When looking at the year of publication of these writings, it is clear that we are talking about an emerging theme. Of the 52 articles analyzed, 19 were published in the year 2021, 24 articles were published in the year 2020, and 9 in the year 2019.

In the sequence, a categorical analysis was carried out, which made it possible to find the following macrocategories for classifying the technologies of Industry 4.0 that support the adoption and implementation of circular economy.

Rent or pay to use

Digital enablers and e-receipt

Sharing

Software as a service

Multi-channel distribution

Digital solutions: for example, visit counters, alexia, etc.

Ethical business

Accuracy, precision, and efficiency

Wearable technologies

Mass customization with technology: personalization of products and services for the end customer

Nanotechnology

Interaction between biological, physical, and technological 
Digitization and IoT: to increase the productivity of the production processes to make the connection close with the customers.

Traceability: use technology to connect and control digitally

3D printing: low cost

Personal assistants who interpret the voice

Machine learning: machine that learns with sensors

Smart sensors: equipment with sensors and a system for detecting the specificities of a product, which facilitates its automatic classification and separation

Big data

Machine learning

Deep learning: use of algorithms for modeling

Smart factory: contributes to closing cycles

Integration of artificial intelligence in production chains

Following this analysis, an empirical-theoretical study was carried out to identify how Brazilian foodtech startups in the agribusiness value chain, farm to table, reuse, and waste management and disposal segment are adopting and implementing technologies related to Industry 4.0 and promoting the integration with circular economy to minimize the effects of resource scarcity in emergency situations. This mapping allowed the elaboration of Table 1. Therefore, Table 1 makes it possible to identify that the technologies of Industry 4.0 are relevant to the success of circular economy. Above all, the role of partnerships is notorious in all foodtech companies analyzed. Not only is the production chain looked at, but also the entire ecosystem and its potential to contribute to the reframing of materials, transformation of waste into resources, retention of value, creation of innovative production alternatives, and marketing and management of the post-use of the various products produced by the foodtech startups. 
Table 1. Technologies of Industry 4.0 and circular economy practices mapped in the foodtech startups.

\begin{tabular}{|c|c|c|c|c|c|c|c|c|c|c|c|c|c|c|c|c|c|c|c|c|c|c|c|c|c|c|c|c|c|c|}
\hline 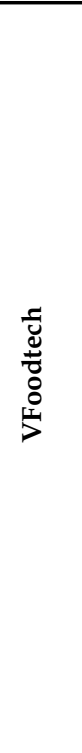 & 㒶 & 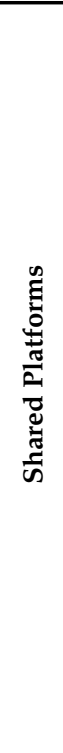 & 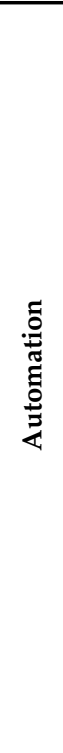 & 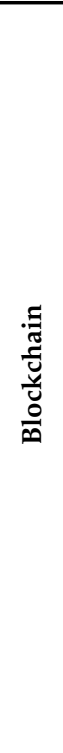 & 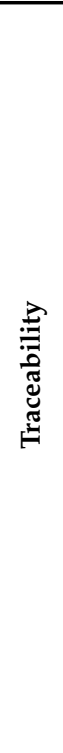 & 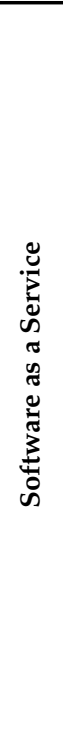 & 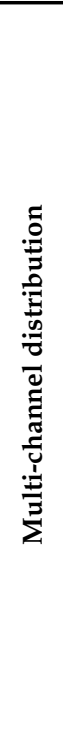 & 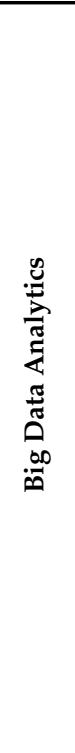 & 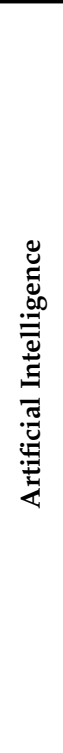 & 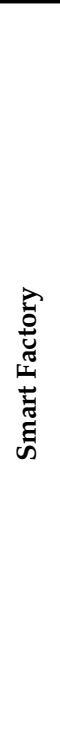 & 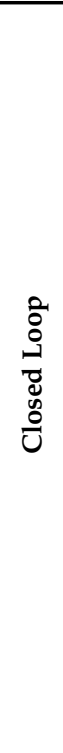 & 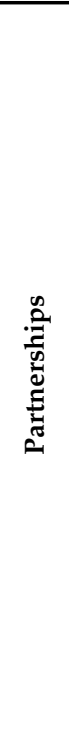 & 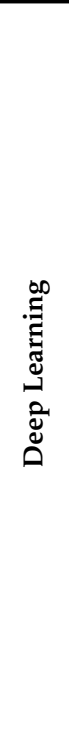 & 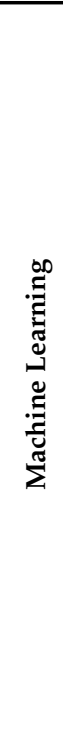 & 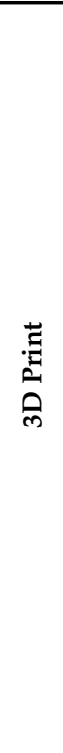 & 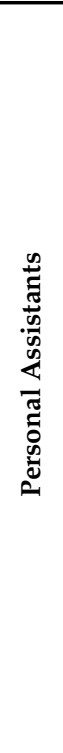 & 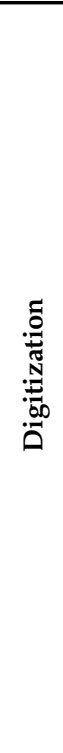 & 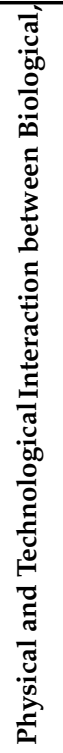 & 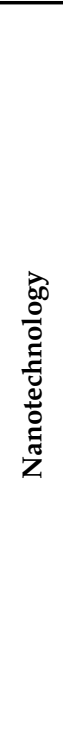 & 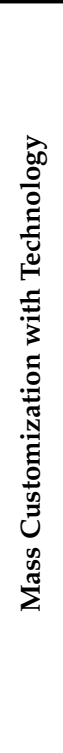 & 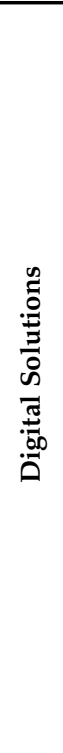 & 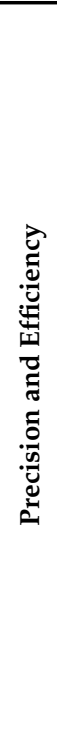 & 弯 & 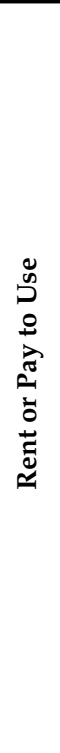 & 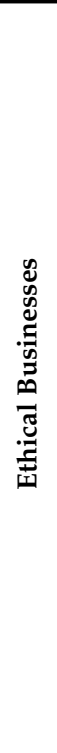 & 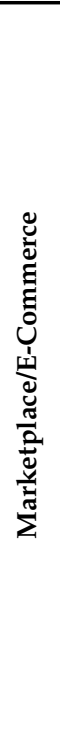 & 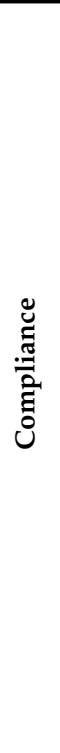 & 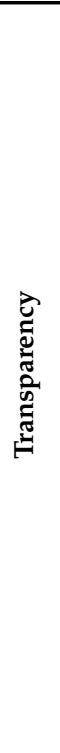 & 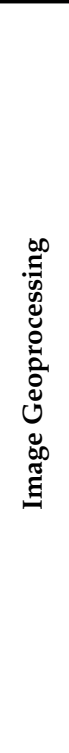 & 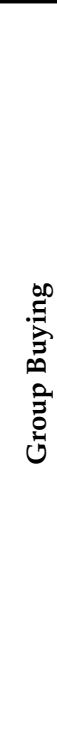 \\
\hline FT02 & & & & $\mathrm{V}$ & $\mathrm{V}$ & $\mathrm{V}$ & & & & & & $\mathrm{V}$ & & & & & $\mathrm{V}$ & & & & & & & & $\mathrm{V}$ & & $\mathrm{V}$ & $\mathrm{V}$ & & \\
\hline $\begin{array}{l}\text { FT03 } \\
\end{array}$ & & & $\mathrm{V}$ & & & $\mathrm{V}$ & & $\mathrm{V}$ & $\mathrm{V}$ & & & $\mathrm{V}$ & $\mathrm{V}$ & & & & $\mathrm{V}$ & $\mathrm{V}$ & & & $\mathrm{V}$ & $\mathrm{V}$ & & & & & $\mathrm{V}$ & $\mathrm{V}$ & $\mathrm{V}$ & \\
\hline $\begin{array}{l}\text { FT04 } \\
\end{array}$ & & & $\mathrm{V}$ & & $\mathrm{V}$ & $\mathrm{V}$ & & $\mathrm{V}$ & $\mathrm{V}$ & $\mathrm{V}$ & & $\mathrm{VV}$ & $\mathrm{V}$ & & & $\mathrm{V}$ & $\mathrm{V}$ & & & & $\mathrm{V}$ & $\mathrm{V}$ & & & & & $\mathrm{V}$ & $\mathrm{V}$ & $\mathrm{V}$ & \\
\hline FT05 & & & & & & $\mathrm{V}$ & & & $\mathrm{V}$ & & & $\mathrm{V}$ & & & & $\mathrm{V}$ & $\mathrm{V}$ & & & & $\mathrm{V}$ & $\mathrm{V}$ & & $\mathrm{V}$ & & & & $\mathrm{V}$ & & \\
\hline FT06 & & $\mathrm{V}$ & & & $\mathrm{V}$ & $\mathrm{V}$ & $\mathrm{V}$ & & & & $\mathrm{V}$ & $\mathrm{V}$ & & & & & & & & & $\mathrm{V}$ & $\mathrm{V}$ & & & & $\mathrm{V}$ & & & & $\mathrm{V}$ \\
\hline FT07 & & & $\mathrm{V}$ & & $\mathrm{V}$ & & & $\mathrm{V}$ & & & & $\mathrm{V}$ & & & & & & & & & $\mathrm{V}$ & $\mathrm{V}$ & & & & & & & & \\
\hline FT08 & $\mathrm{V}$ & $\mathrm{V}$ & & & $\mathrm{V}$ & $\mathrm{V}$ & $\mathrm{V}$ & & & & & $\mathrm{V}$ & & & & & $\mathrm{V}$ & & & & $\mathrm{V}$ & $\mathrm{V}$ & $\mathrm{V}$ & & $\mathrm{V}$ & $\mathrm{V}$ & & & & \\
\hline $\begin{array}{l}\text { FT09 } \\
\end{array}$ & & & & & $\mathrm{V}$ & $\mathrm{V}$ & $\mathrm{V}$ & & & & & $\mathrm{V}$ & & & & & $\mathrm{V}$ & & & & $\mathrm{V}$ & $\mathrm{V}$ & & & & $\mathrm{V}$ & & & & \\
\hline FT10 & $\mathrm{V}$ & $\mathrm{V}$ & & & $\mathrm{V}$ & $\mathrm{V}$ & & & & & & $\mathrm{V}$ & & & & & $\mathrm{V}$ & & & & $\mathrm{V}$ & $\mathrm{V}$ & & & & $\mathrm{V}$ & & & & \\
\hline FT11 & & & & & $\mathrm{V}$ & $\mathrm{V}$ & & & & & & $\mathrm{V}$ & & & & & $\mathrm{V}$ & & & & $\mathrm{V}$ & $\mathrm{V}$ & & & & $\mathrm{V}$ & & $\mathrm{V}$ & & \\
\hline FT12 & & $\mathrm{V}$ & & & $\mathrm{V}$ & $\mathrm{V}$ & $\mathrm{V}$ & & & $\mathrm{V}$ & $\mathrm{V}$ & $\mathrm{V}$ & & & & & $\mathrm{V}$ & $\mathrm{V}$ & $\mathrm{V}$ & & $\mathrm{V}$ & $\mathrm{V}$ & $\mathrm{V}$ & & $\mathrm{V}$ & $\mathrm{V}$ & $\mathrm{V}$ & $\mathrm{V}$ & & \\
\hline FT13 & & $\mathrm{V}$ & & & $\mathrm{V}$ & $\mathrm{V}$ & & & & & $\mathrm{V}$ & $\mathrm{V}$ & & & & & $\mathrm{V}$ & $\mathrm{V}$ & & & $\mathrm{V}$ & $\mathrm{V}$ & & & $\mathrm{V}$ & $\mathrm{V}$ & $\mathrm{V}$ & $\mathrm{V}$ & & \\
\hline FT14 & & $\mathrm{V}$ & & & $\mathrm{V}$ & $\mathrm{V}$ & & & & $\mathrm{V}$ & & $\mathrm{V}$ & & & & & $\mathrm{V}$ & $\mathrm{V}$ & & & $\mathrm{V}$ & $\mathrm{V}$ & & & $\mathrm{V}$ & $\mathrm{V}$ & & & & \\
\hline FT15 & & $\mathrm{V}$ & & & $\mathrm{V}$ & $\mathrm{V}$ & $\mathrm{V}$ & & & & & $\mathrm{V}$ & & & & & $\mathrm{V}$ & & & & $\mathrm{V}$ & $\mathrm{V}$ & $\mathrm{V}$ & & $\mathrm{V}$ & $\mathrm{V}$ & & $\mathrm{V}$ & & $\mathrm{V}$ \\
\hline FT16 & & $\mathrm{V}$ & & & $\mathrm{V}$ & $\mathrm{V}$ & $\mathrm{V}$ & & & $\mathrm{V}$ & $\mathrm{V}$ & $\mathrm{V}$ & & & & & $\mathrm{V}$ & $\mathrm{V}$ & & & $\mathrm{V}$ & $\mathrm{V}$ & $\mathrm{V}$ & & $\mathrm{V}$ & $\mathrm{V}$ & & $\mathrm{V}$ & & $\mathrm{V}$ \\
\hline FT17 & & $\mathrm{V}$ & & & $\mathrm{V}$ & $\mathrm{V}$ & $\mathrm{V}$ & & & & & $\mathrm{V}$ & & & & & $\mathrm{V}$ & $\mathrm{V}$ & & & $\mathrm{V}$ & $\mathrm{V}$ & $\mathrm{V}$ & & $\mathrm{V}$ & $\mathrm{V}$ & & $\mathrm{V}$ & & $\mathrm{V}$ \\
\hline
\end{tabular}




\section{Table 1. Cont.}

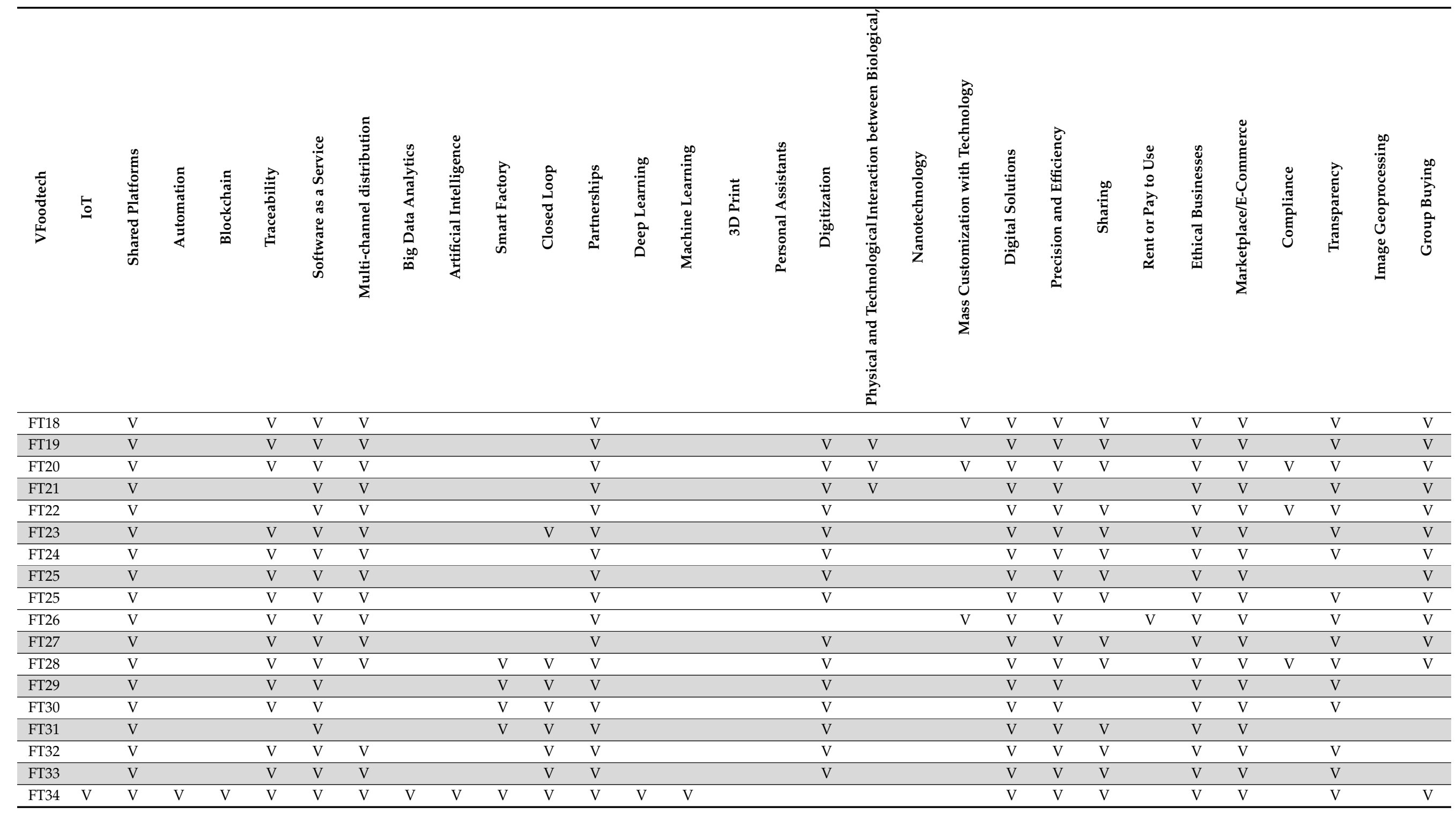




\section{Table 1. Cont.}

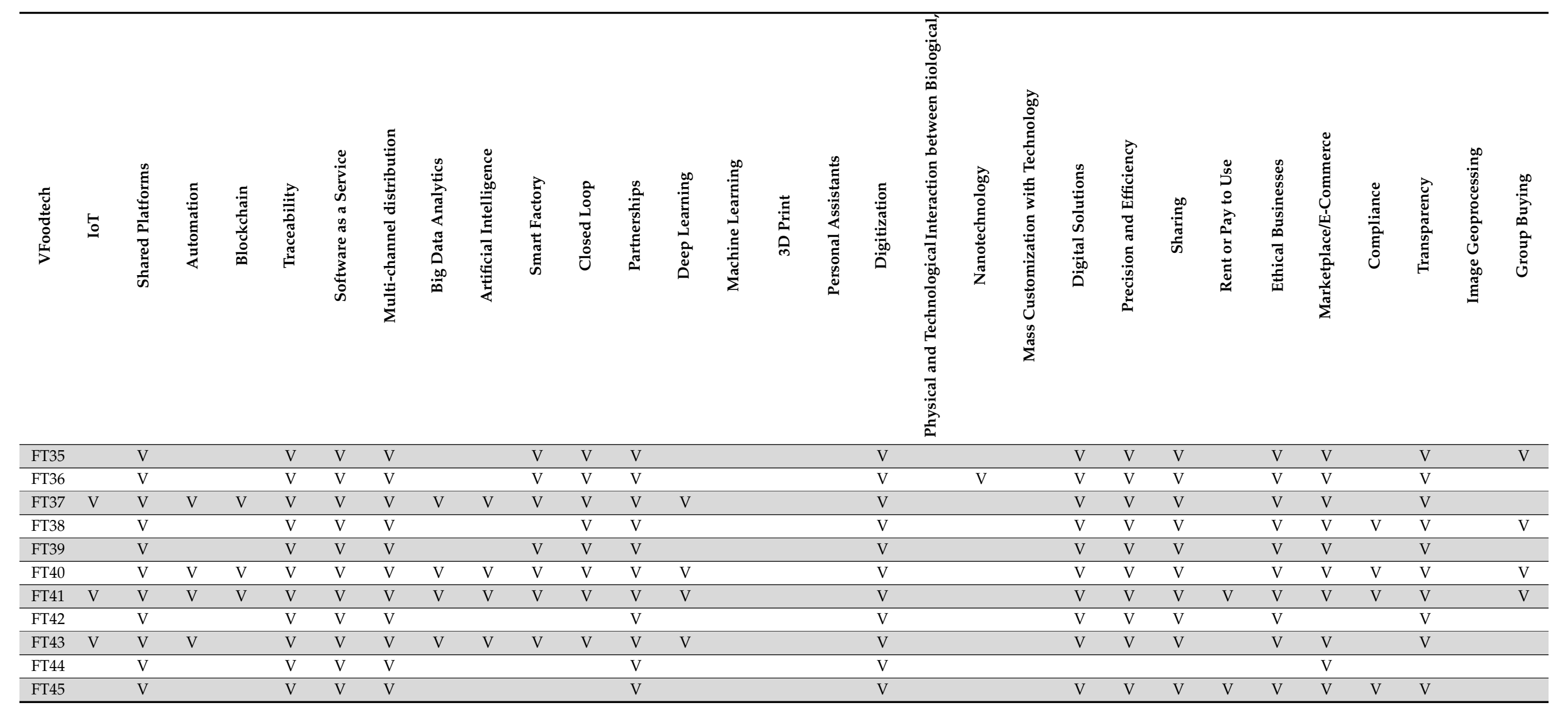




\section{Discussion Section}

With regard to the emergency context, the foodtech startups alluded to the COVID19 pandemic and the social restrictions imposed by this scenario at various times. At other times, allusions were made to climate change, the need to think about sustainable production, the alternatives for achieving sustainable development goals, and the urgency in engaging with alternatives for circular and sustainable production and consumption for the longevity of natural resources on the planet. Therefore, the emergency context addressed by the foodtech startups is associated with an urgent need to think about different, bold, alternative business models that contribute to the intelligent management of productive assets and goods. FT34, for instance, mentions the importance of production, packaging, thinking about connected alternatives, smart packaging solutions, connection through autonomous devices, connectivity with global reach anchored on a platform that uses big data, and artificial intelligence. Thus, this is the way through which productive assets and goods are transformed into intelligent and interconnected artifacts, similar to the statements by [43]. Another solution is smart and sustainable packaging (FT45), with high-load capacity and durability. This facilitates reuse, increases the asset cycle, reduces waste and costs, and provides savings in reverse logistics, as highlighted by [10].

Also noteworthy is the important role of blockchain [44], which adopts a strategic role to enable the efficient and accurate management of solid waste [45] so that they become physical assets for new production chains while providing credits for the industry that produced the waste, be it in the form of plastics, aluminum, or other materials, as highlighted by FT40.

In addition, productive systems of vertical integration (FT24), social valorization through artisanal production (FT20) that strengthens local communities, organic production systems (FT22, FT23), and precision agriculture (FT12) are also organizational contexts that have adhered to Industry 4.0 technologies in a solid way [1,16]. Industry 4.0 and operational research [46] is another example.

It is noteworthy that technologies contribute to reducing the environmental impacts of foodtech startups, contribute to a more efficient management of waste, and generate connectivity between social actors. Therefore, technology plays three roles concomitantly, as it encompasses the economic, social, and environmental pillars of sustainability considering the circularity of resources. Above all, it provides a purpose for companies, generates solutions, allows for creating, innovating, and going beyond the obvious and the known limits in the segments related to the foodtech industry.

The present study allows us to consolidate some theoretical propositions for validation in future empirical studies (Figure 3).

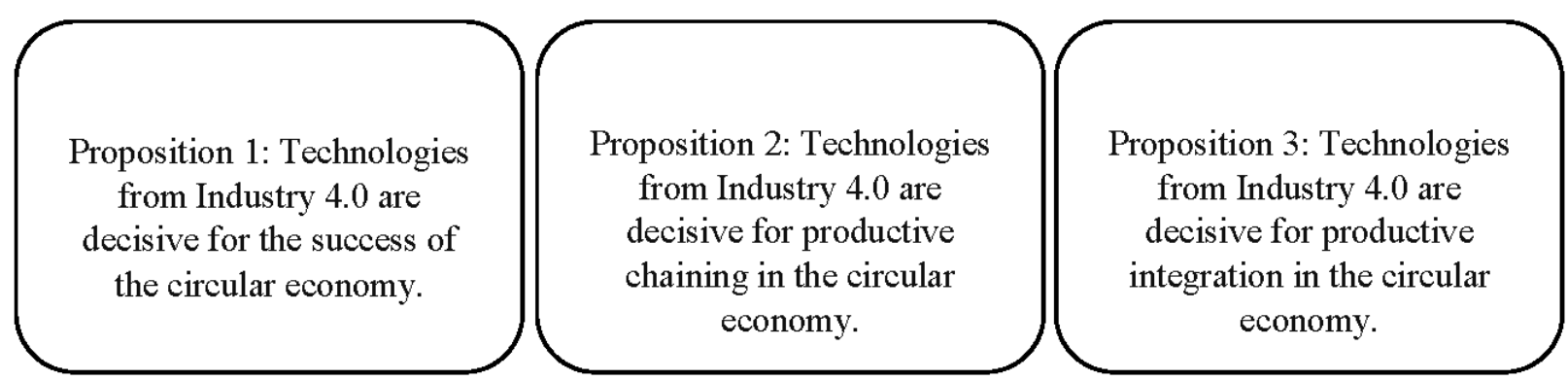

Figure 3. Exploratory framework derived from the empirical research.

The proposed exploratory propositions emerged from the empirical evidence analyzed in this study. They signal the importance, need, and relevance of integrated, connected, and synergistic solutions for a successful circular economy. Validating such propositions through a survey in different geographic contexts and productive sectors can generate relevant insights for the progress of the field of circular economy. 
Based on the substantive evolution promoted by Industry 4.0 and the findings of this study, a relevant research agenda for the sector is proposed. In this agenda, strategic elements are defined for the consolidation of Industry 4.0 technologies for the success of circular economy. Thus, a business and sectoral agenda are presented:

Strengthening partnerships in the ecosystem in which foodtech startups operate: partnerships between universities, the government, unions, associations, banks, NGOs, and development agencies and private companies are essential for the success of the circular economy.

Capacity building: Empowering people to learn how to use the technologies of Industry 4.0 is also essential for the success of the circular economy.

Democratizing access to business models supported by Industry 4.0: Subsidies from the federal government and sectoral cooperation agreements can provide incentives and promote innovative and intelligent technologies.

Sectoral articulation: Incentives for sectoral articulation can stimulate circular ecosystems supported by the technologies of Industry 4.0.

Stimulating the triple helix: The interaction between governments, universities, and businesses can contribute to the dissemination of the technologies of Industry 4.0 and the assumptions of circular economy.

Formalization of sectoral legal guidelines: This allows for the setting of goals and deadlines by those responsible for creating circular supplies and closing the cycle of production chains.

Smart assets as strategic resources: Smart assets are internalized as resources capable of generating differentiation and a competitive advantage for companies.

These are just a few important strategic opportunities to promote innovative and strategic alternatives for the success of the circular economy supported by Industry 4.0 technologies.

\section{Final Remarks}

This study seeks to systematize how organizations are adopting and implementing technologies related to Industry 4.0 and promoting the integration with circular economy to minimize the effects of resource scarcity in emergency situations. It is well known that the efficient approaches generated by these technological resources contribute to optimizing manufacturing costs with improved quality and shorter waiting times. Efficient approaches are essential for improving productivity, accuracy, reliability, decision making, monitoring, and flexibility. In addition, manufacturing industries can use these artifacts to unlock the closed cycle of resources in supply chains and to manage sustainable operations. This provides a different perspective from $\mathrm{CE}$, as it meets the dematerialization guidelines to achieve sustainable production and consumption by renewing the value of the resources used.

\subsection{Practical Contribution}

The practical contribution of this study consists of mapping the technologies of Industry 4.0 adopted by the foodtech startups for the success of the circular economy. These companies, whose majority was born just a few years ago, are already explicit in their media communications and websites about the synergies they have with circular economy. Most of these businesses were already born supported by the assumptions of circular economy. Others, despite not explicitly in their communication channels, have clear evidence of alignment with the assumptions of circular economy. Technologies based on the principles of Industry 4.0 make it possible to overcome CE inhibitors and balance the pillars of CE in the environmental, economic, and social dimensions.

\subsection{Theoretical Contribution}

The theoretical contribution relies on the affirmation that foodtech startups are the protagonists of the adhesion to circular economy, enabled the technologies of Industry 4.0. It appears that Industry 4.0 and circular economy generate productive chains, innovative 
and productive ecosystems, intelligent assets, and many new features for the market. It is an evolution compared to traditional businesses, capable of revolutionizing society once there is a scale dissemination of these alternatives. Thus, scalability and capillarity are relevant alternatives to reduce technology costs and energy consumption, while increasing circular supply and work efficiency. They activate the circular economy by creating agile, precise systems, generating circularity metrics, data for human-machine decision making, and intelligent assets.

The limitations of the study are associated with information coverage, which may not have been fully carried out. Other technologies of Industry 4.0 may be used by foodtech companies, but this study was unable to map in a timely manner through the channels and methods foreseen to carry out this work. As an opportunity for future studies, we recommend the development of propositions based on this study for validation in other empirical organizational contexts. The comparison between early entrants and late entrants can lead to know-how lessons obtained by the adopters of technologies of Industry 4.0 and $\mathrm{AI}$ in the context of CE.

Author Contributions: All sections were produced in collaboration with the two authors. All authors have read and agreed to the published version of the manuscript.

Funding: CNPQ.

Institutional Review Board Statement: No applicable.

Informed Consent Statement: Informed consent was obtained from all subjects involved in the study. Yes, the subjects informed consent statement for the research.

Data Availability Statement: Data is available. Will be sent if requested.

Conflicts of Interest: The authors declare no conflict of interest.

\section{References}

1. Lucarini, V.; Bódai, T. Edge states in the climate system: Exploring global instabilities and critical transitions. Nonlinearity 2017, 30, 32-66. [CrossRef]

2. Saadat, S.; Rawtani, D.H.; Chaudhery, M. Environmental perspective of COVID-19. Sci. Total Environ. 2020, 728, 138-154. [CrossRef] [PubMed]

3. Houghton, J.T.; Jenkins, G.J.; Ephraums, J.J. Climate Change; ETDEWEB: London, UK, 1990.

4. Uzoejinwa, B.B.; He, X.; Wang, S.; El-Fatah, A.A.; Hu, Y.; Wang, Q. Co-pyrolysis of biomass and waste plastics as a thermochemical conversion technology for high-grade biofuel production: Recent progress and future directions elsewhere worldwide. Energy Convers. Manag. 2018, 163, 468-492. [CrossRef]

5. Sehnem, S.; Pereira, S.C.F.; Godoi, D.; Pereira, L.H.; Santos Junior, S. Food waste management: An analysis from the circular economy perspective. Environ. Qual. Manag. 2020, 12, 1-23. [CrossRef]

6. Brown, C. Politics and the Environment: Nonlinear Instabilities Dominate. Am. Political Sci. Rev. 1994, 88, 292-303. [CrossRef]

7. Alexander, D. Natural Disasters; Routledge: New York, NY, USA, 2018.

8. Massaro, M.; Secinaro, S.; Mas, F.D.; Brescia, V.; Calandra, D. Industry 4.0 and circular economy: An exploratory analysis of academic and practitioners' perspectives. Bus. Strategy Environ. 2020, 1, 1-19. [CrossRef]

9. Belanche, D.; Casaló, L.V.; Flavián, C. Artificial Intelligence in FinTech: Understanding robo-advisors adoption among customers. Ind. Manag. Data Syst. 2019, 119, 1411-1430. [CrossRef]

10. Rajput, S.; Singh, S.P. Industry 4.0 Model for circular economy and cleaner production. J. Clean. Prod. 2020, 277, 123-139. [CrossRef]

11. Díaz-Chao, Á.; Ficapal-Cusí, P.; Torrent-Sellens, J. Environmental assets, industry 4.0 technologies and firm performance in Spain: A dynamic capabilities path to reward sustainability. J. Clean. Prod. 2020, 281, 125-264. [CrossRef]

12. Ma, S.; Zhang, Y.; Yang, H.; Lv, J.; Ren, S.; Liu, Y. Data-driven sustainable intelligent manufacturing based on demand response for energy-intensive industries. J. Clean. Prod. 2020, 274, 123-255. [CrossRef]

13. Cwiklicki, M.; Wojnarowska, M. Circular Economy and Industry 4.0: One-Way or Two-Way Relationships? Inz. Ekon.-Eng. Econ. 2020, 31, 387-397. [CrossRef]

14. Ellen MacArthur Foundation. Towards the circular economy. J. Ind. Ecol. 2013, 1, 4-8.

15. Bag, S.; Gupta, S.; Kumar, S. Industry 4.0 adoption and 10R advance manufacturing capabilities for sustainable development. Int. J. Prod. Econ. 2021, 231, 231-244. [CrossRef]

16. Gavrila, S.; Ancillo, A.L. Spanish SMEs' digitalization enablers: E-Receipt applications to the offline retail Market. Technol. Forecast. Soc. Chang. 2021, 162, 120381. [CrossRef] [PubMed] 
17. Sandberg, E.; Hultberg, E. Dynamic capabilities for the scaling of circular business model initiatives in the fashion industry. J. Clean. Prod. 2021, 320, 128-142. [CrossRef]

18. Shayganmehr, M.; Kumar, A.; Garza-Reyes, J.A.; Moktadir, M.A. Industry 4.0 Enablers for a Cleaner Production and Circular Economy within the context of Business Ethics: A Study in a Developing Country. J. Clean. Prod. 2020, 14, 125-138. [CrossRef]

19. Manavalan, E.; Jayakrishna, K. A review of Internet of Things (IoT) embedded Sustainable Supply Chain for Industry 4.0 requirements. Comput. Ind. Eng. 2018, 9, 169-189. [CrossRef]

20. Fosso-Wamba, S.; Bawack, R.E.; Guthrie, C.; Queiroz, M.M.; Carillo, K.D.A. Are we preparing for a good AI society? A bibliometric review and research agenda. Technol. Forecast. Soc. Chang. 2021, 164, 120-182. [CrossRef]

21. Kristoffersen, E.; Blomsma, F.; Mikalef, P.; Li, J. The smart circular economy: A digital-enabled circular strategies framework for manufacturing companies. J. Bus. Res. 2020, 120, 241-261. [CrossRef]

22. Corona, B.; Shen, L.; Reike, D.; Rosales Carreón, J.; Worrell, E. Towards sustainable development through the circular economy-A review and critical assessment on current circularity metrics. Resour. Conserv. Recycl. 2019, 151, 104-149. [CrossRef]

23. Roy, V.; Silvestre, B.S.; Singh, S. Reactive and proactive pathways to sustainable apparel supply chains: Manufacturer's perspective on stakeholder salience and organizational learning toward responsible management. Int. J. Prod. Econ. 2020, 8, 107-120. [CrossRef]

24. Fosso-Wamba, S.; Queiroz, M.M.; Guthrie, C.; Braganza, A. Industry experiences of artificial intelligence (AI): Benefits and challenges in operations and supply chain management. Prod. Plan. Control 2021, 1-13, Ahead of print. [CrossRef]

25. Wang, N.; Ren, S.; Liu, Y.; Yang, M.; Wang, J.; Huisingh, D. An active preventive maintenance approach of complex equipment based on a novel product-service system operation mode. J. Clean. Prod. 2020, 277, 1-25. [CrossRef]

26. Queiroz, M.M.; Fosso-Wamba, S.; Machado, M.C.; Telles, R. Smart production systems drivers for business process management improvement. Bus. Process Manag. J. 2020, 26, 1075-1092. [CrossRef]

27. Jabbour, C.J.C.; Fiorini, P.D.C.; Ndubisi, N.O.; De Queiroz, M.M.; Piato, É.L. Digitally-enabled sustainable supply chains in the 21st century: A review and a research agenda. Sci. Total Environ. 2020, 725, 138-177.

28. Fatimah, Y.A.; Govindan, K.; Murniningsih, R.; Setiawan, A.A. Sustainable circular economy approach for smart waste management system to achieve sustainable development goals: Case study in Indonesia. J. Clean. Prod. 2020, 269, 122-169. [CrossRef]

29. Sehnem, S.; de Queiroz, A.A.F.S.; Pereira, S.C.F.; dos Santos Correia, G.; Kuzma, E. Circular Economy and Innovation: A look from the perspective of organizational capabilities. Bus. Strategy Environ. 2021, 31, 236-250. [CrossRef]

30. Scarpellini, S.; Valero-Gil, J.; Moneva, J.M.; Andreaus, M. Environmental management capabilities for a circular eco-innovation. Bus. Strategy Environ. 2020, 3, 1-17. [CrossRef]

31. Kristoffersen, E.; Mikalef, P.; Blomsma, F.; Li, J. The effects of business analytics capability on circular economy implementation, resource orchestration capability, and firm performance. Int. J. Prod. Econ. 2021, 239, 1-25. [CrossRef]

32. Christensen, C.M. The ongoing process of building a theory of disruption. J. Prod. Innov. Manag. 2006, 23, 39-55. [CrossRef]

33. Fernandes, J.A.L.; Sousa-Filho, J.M.; Viana, F.L.E. Sustainable Business Models in a Challenging Context: The Amana Katu Case. J. Contemp. Adm. 2021, 25, 1-17. [CrossRef]

34. Julianelli, V.; Caiado, R.G.G.; Scavarda, L.F.; de Cruz, S.P.M.F. Interplay between reverse logistics and circular economy: Critical success factors-based taxonomy and framework. Resour. Conserv. Recycl. 2020, 158, 104-132. [CrossRef]

35. Kalmykova, Y.; Sadagopan, M.; Rosado, L. Circular economy-From review of theories and practices to development of implementation tools. Resour. Conserv. Recycl. 2018, 135, 190-201. [CrossRef]

36. Kearney, A.T. Readiness for the Future of Production Report 2018; World Economic Forum: Cologny, Switzerland, 2018.

37. Kerin, M.; Pham, D.T. A review of emerging industry 4.0 technologies in remanufacturing. J. Clean. Prod. 2019, $237,117805$. [CrossRef]

38. Kouhizadeh, M.; Zhu, Q.; Sarkis, J. Blockchain and the circular economy: Potential tensions and critical reflections from practice. Prod. Plan. Control 2019, 31, 950-966. [CrossRef]

39. Lu, Y.; Xu, X. Cloud-based manufacturing equipment and big data analytics to enable on-demand manufacturing services. Robot. Comput. Integr. Manuf. 2019, 47, 92-102. [CrossRef]

40. Jayakumar, J.; Jayakrishna, K.; Vimal, K.E.K.; Hasibuan, S. Modelling of sharing networks in the circular economy. J. Model. Manag. 2020, 15, 407-440. [CrossRef]

41. Hoon, C. Meta-Synthesis of Qualitative Case Studies. Organ. Res. Methods 2013, 16, 522-556. [CrossRef]

42. Yin, R.K. Pesquisa Qualitativa do Início ao Fim; Penso: Porto Alegre, Brazil, 2016.

43. Erro-Garcé, A. Industry 4.0: Defining the research agenda. Benchmarking Int. J. 2019, 28, 1858-1882. [CrossRef]

44. Clohessy, T.; Acton, T. Investigating the influence of organizational factors on blockchain adoption: An innovation theory perspective. Ind. Manag. Data Syst. 2019, 119, 1457-1491. [CrossRef]

45. Yadav, G.; Luthra, S.; Jakhar, S.; Mangla, S.K.; Rai, D.P. A framework to overcome sustainable supply chain challenges through solution measures of industry 4.0 and circular economy: An automotive case. J. Clean. Prod. 2020, 254, 112-120. [CrossRef]

46. Widjajanto, S.; Purba, H.H.; Jaqin, S.C. Novel POKA-YOKE approaching toward industry-4.0: A literature review. Oper. Res. Eng. Sci. Theory Appl. 2020, 3, 65-83. [CrossRef] 